\title{
A randomized controlled trial to compare aesthetic outcomes of immediately placed implants with and without immediate provisionalization
}

\author{
Hsun-Liang Chan ${ }^{1}$ (D) | Furat George ${ }^{2}$ | I-Ching Wang ${ }^{1}$ | \\ Fernando Suárez López del Amo ${ }^{1}$ | Janet Kinney ${ }^{1}$ | Hom-Lay Wang ${ }^{1}$ (ID
}

${ }^{1}$ Department of Periodontics and Oral Medicine, University of Michigan School of Dentistry, Ann Arbor, Michigan, USA

${ }^{2}$ Department of Biologic and Materials Sciences and Prosthodontics, University of Michigan School of Dentistry, Ann Arbor, MI, USA

\section{Correspondence}

Hom-Lay Wang, Department of Periodontics and Oral Medicine, University of Michigan, School of Dentistry, 1011 North University Avenue, Ann Arbor, MI 48109-1078, USA.

Email: homlay@umich.edu

Funding information

University of Michigan Graduate Student

Research Grant

\begin{abstract}
Introduction: There are mixed results regarding the aesthetic advantage of immediate provisionalization of dental implants. Therefore, this study aimed to compare facial mucosal level of single immediately placed implants with and without immediate provisionalization.

Methods: Single implants were immediately placed to replace a hopeless maxillary anterior or premolar tooth in 40 subjects. Each implant was randomly assigned to receive a non-occluding temporary crown or a healing abutment after implant placement. At 4 months, these implants were permanently restored and followed up for 12 months. Clinical and radiographic parameters were measured and compared.

Results: The implant survival rate at 12 months in the test and control group was $90 \%$ and $100 \%$, respectively. Mid-facial mucosal marginal level and papilla height changes were minimal within groups, and no significant differences were found between the two groups. The amount of marginal bone remodelling was modest, with no significant difference between the two groups. Radiographic bone changes were not statistically different between the groups, except for the vertical crestal bone resorption.

Conclusion: Immediate implant placement with or without provisionalization can achieve stable vertical soft tissue level for 12 months as compared to pre-extraction level. However, immediate provisionalization was not able to improve the aesthetic outcome further.
\end{abstract}

\section{KEYWORDS}

cone beam computed tomography, dental implants, mucosa recession, implant survival, marginal bone loss 


\section{1 | INTRODUCTION}

Immediate implant placement has become a predictable procedure due to the improvement in implant surface treatment and understanding of implant healing. Numerous clinical trials (Chen, Wilson, \& Hammerle, 2004; Cosyn, De Bruyn, \& Cleymaet, 2013; Cosyn et al., 2011; Cosyn, Hooghe, \& De Bruyn, 2012; Gallucci, Hamilton, Zhou, Buser, \& Chen, 2018; Kan, Rungcharassaeng, \& Lozada, 2005) have proven the predictability of this approach, with survival rate similar to the conventional approach, provided with prudent case selection and treatment planning. This approach was believed to preserve alveolar bone around the implant, but this failed to hold true, as evidenced by preclinical (Araujo, Linder, \& Lindhe, 2011) as well as clinical (Botticelli, Berglundh, \& Lindhe, 2004) studies. Alveolar bone continues to remodel after an implant is placed in a fresh socket. A recent long-term follow-up study further pointed out immediate implant placement may result in an increased risk of facial mucosa recession (Cosyn et al., 2012; Kan, Roe, et al., 2011). On the other hand, some studies suggested this approach might actually reduce facial mucosa recession, especially when the implants were also immediately provisionalized (Cosyn et al., 2013, 2011). Thus, the impact of combined treatment on facial soft tissue level remains undetermined.

Some local factors might have contributed to the observed controversy in the literature (Lin, Chan, Bashutski, Oh, \& Wang, 2014). Among them, different positioning of the implant might be one of the major confounders that influences the outcome. Immediately placed implants have a tendency to shift facially compared with the initial drill trajectory because it follows the pathway with the least resistance (Koticha, Fu, Chan, \& Wang, 2012). Buccally placed implants have three times more mucosal recession than normal or ideal placed implant (Evans \& Chen, 2008). Additionally, tissue phenotype might be associated with the amount of recession after implant placement. It has been known that thin mucosa is more prone for recession (Claffey \& Shanley, 1986; Fu et al., 2010) and patients with a thin mucosa tissue are at a higher risk for aesthetic failures after receiving immediately placed implants (Kan, Rungcharassaeng, Lozada, \& Zimmerman, 2011). Surgical modifications have been proposed to overcome potential recession, that is connective tissue graft and a flapless surgery. Lastly, buccal plate thickness plays a determining role for the stability of its overlying soft tissue. A thicker buccal plate might resist bone resorption more effectively (Ferrus et al., 2010). Furthermore, it is suggested at least $2 \mathrm{~mm}$ thick buccal bone is necessary for a stable dimension of facial mucosa (Miyamoto \& Obama, 2011). Unpredictable bone remodelling after immediate implant placement, especially in situations where there is a buccal wall defect, might be one of the reasons for mid-facial soft tissue recession (Kan, Rungcharassaeng, Sclar, \& Lozada, 2007).

Immediate implant provisionalization is defined as when an implant is restored within $48 \mathrm{hr}$ after implant placement (Cochran, Morton, \& Weber, 2004). An obvious advantage is to restore aesthetics immediately with a fixed solution. A recent systematic review (Suarez, Chan, Monje, Galindo-Moreno, \& Wang, 2013) suggested that the timing

\section{Clinical Relevance}

Scientific Rationale for the Study: Conflicting evidence exists relating to the benefits of immediate provisionalization on preserving soft tissue level around immediately placed implants. Provisional restorations may provide necessary mechanical support to the soft tissue and therefore maintain its level.

Principal findings: Immediately placed implants with or without immediate provisionalization achieved functional as well as aesthetic success, evaluated by multiple clinical and radiographic parameters in short term. Immediate provisionalization did not significantly improve mucosal margin level, papilla height and the aesthetic score, compared with delayed restoration.

Practical implications: Immediate implant placement can maintain stable vertical soft tissue level compared with pre-extraction level. Immediate provisionalization may not provide additional aesthetic benefits.

of the restoration does not influence marginal bone level around implants. However, immediate provisionalization might preserve papilla height (Oh, Shotwell, Billy, \& Wang, 2006) and the mid-facial mucosal level (Cosyn et al., 2011). Therefore, the hypothesis of this randomized controlled trial is that immediate provisionalization had better implant aesthetic outcome and less mid-facial recession than the delayed restoration of immediately placed implants. The primary objective of this study is the mid-facial mucosal position changes. Secondary outcome assessments include interproximal papilla level changes, implant aesthetic scores, marginal bone level changes on 2-dimensional radiographs and crestal bone changes based on CBCT analysis.

\section{2 | MATERIALS AND METHODS}

\section{1 | Patient selection criteria}

The study was approved under the number HUM00070747 by the University of Michigan Institutional Review Board (IRB) and registered at clinicaltrial.org with registration number NCT01925339. A total number of 40 subjects (see "Statistics session" for sample size calculation) in need of a single implant restoration for single hopeless natural tooth (second premolar to second premolar) in the maxilla due to non-restorable caries, root fracture and root resorption or trauma were recruited. A cone beam computed tomography (CBCT) scan (3D Accuitomo 170 unit, JMorita Corp.) with $80 \mu \mathrm{m}$ voxel resolution was acquired at baseline $\left(T_{0}\right)$ to assess the buccal dehiscence/fenestration prior to the implant surgery. The second scan was taken at final crown delivery $\left(T_{1}\right)$. The other inclusion criteria were as follows: age $\geq 21$, a minimum of 20 permanent teeth present, at least $4 \mathrm{~mm}$ bone apical to the root apex of the hopeless tooth, adjacent natural tooth presented 
FIGURE 1 Study flow chart indicating screening visits, randomization and allocation and numbers of subjects available for data analysis

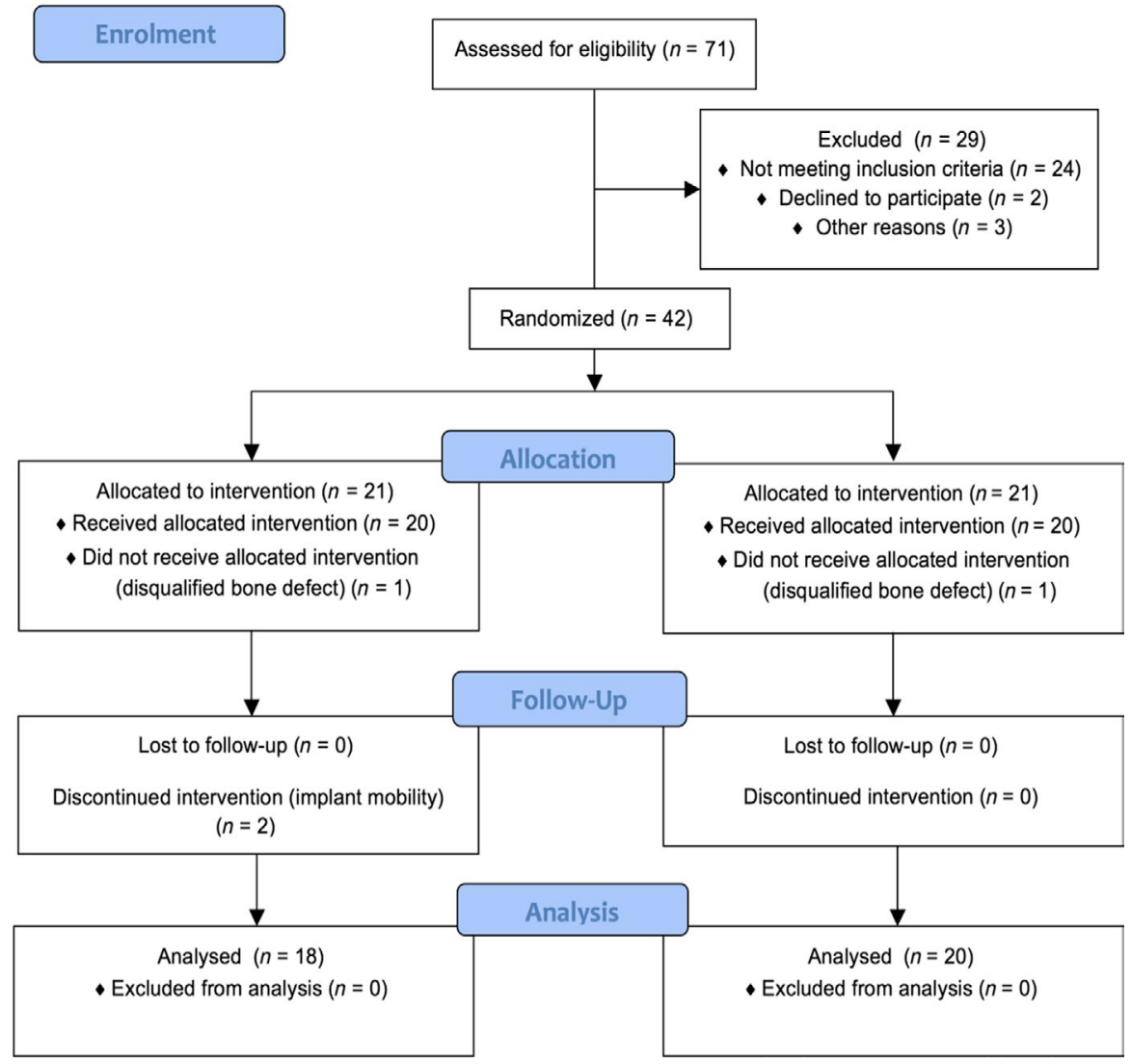

with healthy periodontium, and enough mesio-distal and apico-coronal space for an implant crown. Exclusion criteria were as follows: missing more than $4 \mathrm{~mm}$ of facial plate height, current or former (quitted less than 1 year ago) smokers, observable gingival changes due to use of medications (e.g. calcium channel blockers, anticonvulsives, immunosuppressants, anti-inflammatory medications or oral contraceptives), presence of systemic diseases that may affect wound healing (e.g. uncontrolled diabetes (HbA1c > 7\%), neurologic or psychiatric disorders, systemic infections, pregnant or plan to get pregnant or lactating mothers, current alcoholism or drug abuse, radiation therapy within 3 years, current use of oral bisphosphonates for $>3$ years, history of IV bisphosphonates use) and acute infection at/or adjacent to the extraction site (e.g. sinus tract, swelling, untreated deep carious lesions or defective restorations, uncontrolled periodontal disease and poor oral hygiene (>20\% full-mouth plaque score)).

Figure 1 shows the experimental flow chart indicating screening visits, randomization and allocation and numbers of subjects available for data analysis.

\section{2 | Baseline surgical procedures}

At the pre-implant visit, every eligible tooth was measured for pocket depth, plaque index, gingival index, pink aesthetic score (PES) (Furhauser et al., 2005) and width of keratinized mucosa. One periodontist $(\mathrm{HW})$ atraumatically extracted all the hopeless teeth without raising the flap. The periodontal probe (UNC-15 probe, Hu-Friedy) was used to measure the depth/width of buccal dehiscence and socket, mid-facial mucosa and papilla level from the custom-made acrylic stent as well as referencing line drawn by the adjacent teeth. The thickness of buccal/palatal bone plate at $1 \mathrm{~mm}$ apical to crest and the thickness of gingiva at $2 \mathrm{~mm}$ from free gingival margin were recorded using bone/wax caliper (Iwanson caliper, Hu-Friedy). Tapered, internal-connection with $0.5 \mathrm{~mm}$ smooth collar implant, length of 11.5-13 mm (IS II active, Neobiotech) was immediately inserted following manufacturer's instructions in each qualified subject. Implant diameter (3.5, 4.0 or $4.5 \mathrm{~mm}$ ) was determined according to socket size in order to achieve $>1.5 \mathrm{~mm}$ mesiodistally implant-tooth distance. All implants were placed aiming at the cingulum position when possible, $3 \mathrm{~mm}$ below the mucosal margin, and achieved primary stability of at least $30 \mathrm{Ncm}$. After implant placement, the distance from implant platform to the facial mucosal margin (implant vertical position) and to the inner surface of buccal/ lingual bone plate (size of buccal/palatal gap) was recorded. The gap between the implant and socket wall was filled with human cancellous particulate allograft (Puros ${ }^{\circledR}$, Zimmer Biomet). These implants were then assigned into one of the two groups: immediate temporization (Test group) or temporary abutment (Control group) with a simple randomization method. One independent examiner (JK) performed randomized allocation and concealment. The simple random sequence was generated by computer software, and allocation was accomplished by using sealed envelopes with an equal number of envelopes for each group. Allocation was revealed only after implants were placed and post-implant measurement was carried out. The following radiographic analysis and data statistics were completed 
by concealing the corresponding clinical data from the independent examiner to avoid bias towards measurement. Calibrated exercise and custom-made stent training were performed before the study.

The test implants were restored immediately by a prosthodontist (FG) with a pre-fabricated titanium temporary abutment (Neobiotech) and screw-retained provisional crown with flat or concave emergence profile, and any occlusal contacts were avoided during centric or excursive movements (Figure 2). For the control implant, an abutment with a size that is closest to the socket was placed and a collagen dressing (Zimmer ${ }^{\circledR}$ Colla- Tape, Zimmer Biomet) was used to cover the bone graft. Essix appliances were used as temporary restoration when feasible. An implant-level impression was carried out in both groups at approximately 4 months after the implant surgery by the same prosthodontist. The emergence profile of the provisional crowns on test implants was transferred via bite registration material (Blue-Bite, Henry Schein Inc.), and the final ceramic crowns and titanium-based ceramic abutments were cemented after the radiographic validation of fully seating (Figure 2 ).

\section{3 | Primary and secondary outcome measures}

The primary outcome is the mid-facial mucosal level changes. A single calibrated examiner $(\mathrm{HC})$ performed all the clinical measurements during the surgical visit, post-op 2 weeks and one-month,

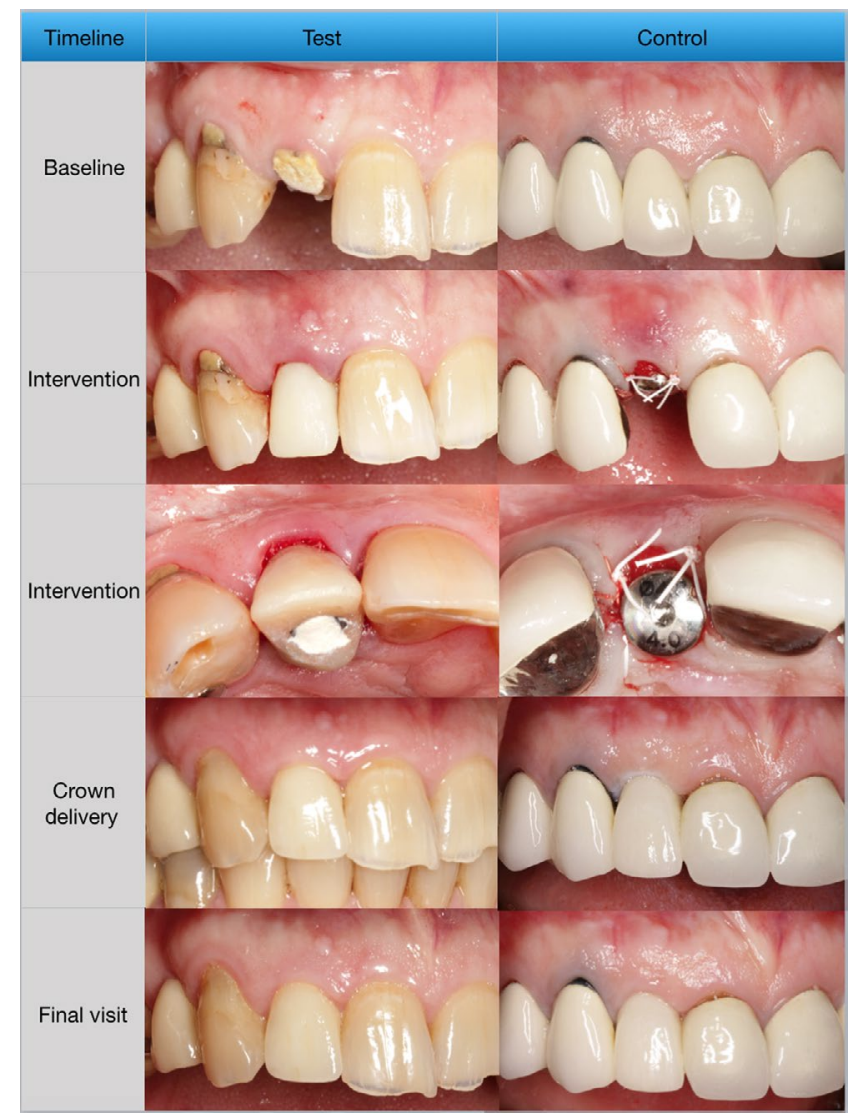

FIGURE 2 Clinical photographs demonstrating the treatment steps and relatively stable soft tissue levels for both the test and control groups permanent crown delivery visit (T1) and final visit at 12 months (T2). The mucosal level was primarily determined by drawing an imaginary line connecting the free gingival margins of the immediately adjacent teeth and secondarily measured from a custom-made, light-cured reference stent using periodontal probe (UNC-15 probe, Hu-Friedy) with approximation to $0.5 \mathrm{~mm}$. If a discrepancy between the 2 methods was noticed, standardized photographs and study models were examined to resolve the discrepancy. Secondary outcomes include tooth-related parameters, such as papilla height, probing depth, gingival recession, plaque index, gingival index and keratinized mucosa width. At $T_{1}$ and $T_{2}$, in addition to previously mentioned parameters, the white/pink aesthetic scores (WES/PES) were measured (Furhauser et al., 2005).

\section{4 | Radiographic examinations}

Standardized digital peri-apical films were taken by using a long cone parallel technique at implant placement $\left(T_{0}\right)$, temporary abutment or healing abutment insertion, permanent crown seating (T1) and final visit (T2) (Figure 3). A customized radiographic stent was fabricated before tooth extraction comprised of XCP bite-block (Dentsply Rinn, Henry Schein, Inc.) and bite registration material (Blue-Bite, Henry Schein Inc.). An independent calibrated examiner (IW) measured mesial and distal marginal bone level with built-in analysis software on a 27-inch computer screen in an independent room designed for
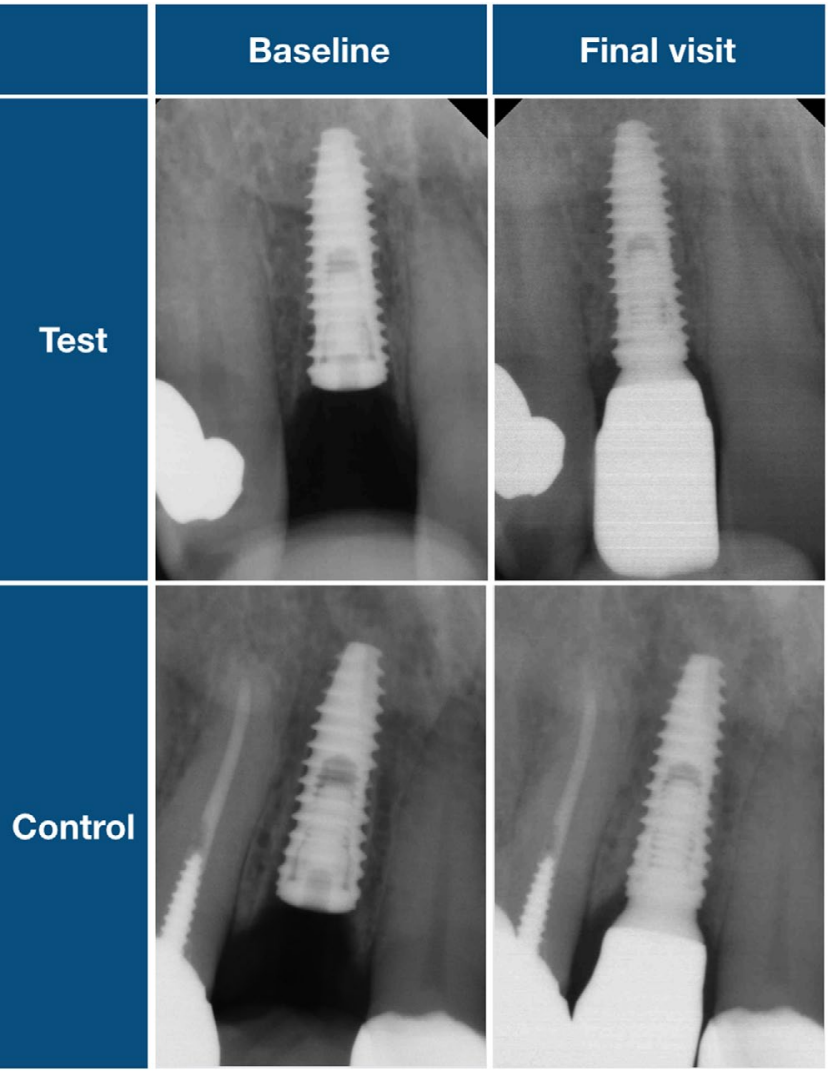

FIGURE 3 Radiographs demonstrating the marginal bone level at baseline, type of intervention delivered at baseline and at the final visit 
image reading. The length of the implant was used to calibrate the measurements. The marginal bone loss was evaluated using the implant platform (platform switching junction) as the reference level, and the averaged mesial and distal changes were used as the final estimate for each implant. Using the automated imaging software (Invivo Dental 5, Anatomage), voxel-based superimposition of two serial CBCT scans was performed to linearly measure the spatial (vertical and horizontal) changes in alveolar bone crest and bone thickness reduction at the implant platform, and 2-mm incremental to $8 \mathrm{~mm}$ above the platform at the cross-section plane through implant. The interexaminer agreement was $>90 \%$ within $0.2 \mathrm{~mm}$ by repeating measurement 20 times.

\section{5 | Statistical analysis}

Based on the previous similar study (Raes, Cosyn, Crommelinck, Coessens, \& De Bruyn, 2011), a mean difference of $0.8 \mathrm{~mm}$ mucosal level and standard deviation of $0.8 \mathrm{~mm}$ were estimated to acquire $80 \%$ power and 5\% type 1 error in power calculation, and a sample size of 18 subjects in each group was rendered. Taking into account of an estimated $10 \%$ dropout rate, a sample size of total 40 subjects was selected. Demographic, clinical and radiographic parameters were recorded and described as mean values and standard deviations. The Shapiro-Wilk test of normality was utilized to verify the normal distribution of observing data, and all the statistical tests were performed by a software package (SPSS Version 25, Statistical Package for Social Sciences; SPSS Inc). Baseline variables were compared across two groups with chisquared test for categorical variables and the non-paired Student $t$ test for continuous variables. Changes in the parameters over time within each group as well as differences between groups were analysed using
TAB LE 1 Baseline demographic and clinical parameters

\begin{tabular}{llll}
\hline Mean \pm SD) & Test $(n=18)$ & $\begin{array}{l}\text { Control } \\
(n=20)\end{array}$ & $p$-value \\
\hline Age & $60.4 \pm 12.0$ & $57.9 \pm 15.0$ & 0.57 \\
Gender (male/female) & $8 / 10$ & $10 / 10$ & 0.73 \\
\hline M-D socket width & $6.4 \pm 1.2$ & $6.5 \pm 1.5$ & 0.71 \\
\hline B-L socket width & $7.2 \pm 2.2$ & $7.8 \pm 2.2$ & 0.72 \\
\hline KG width & $5.3 \pm 1.7$ & $6.1 \pm 1.8$ & 0.18 \\
\hline $\begin{array}{l}\text { Mid-facial KG } \\
\text { thickness }\end{array}$ & $0.6 \pm 0.2$ & $0.7 \pm 0.4$ & 0.38 \\
\hline $\begin{array}{c}\text { Buccal bone dehis- } \\
\text { cence depth }\end{array}$ & $1.0 \pm 1.1$ & $0.5 \pm 0.7$ & 0.08 \\
\hline $\begin{array}{l}\text { Implant apico-coronal } \\
\text { position }\end{array}$ & $2.7 \pm 0.7$ & $3.4 \pm 0.6$ & $0.004^{*}$ \\
\hline \begin{tabular}{l} 
Buccal gap \\
\hline
\end{tabular} & $2.6 \pm 0.8$ & $2.7 \pm 0.8$ & 0.8 \\
\hline
\end{tabular}

*indicates significant difference between two groups $(p<0.05)$.

the two-way mixed ANOVA with post hoc Bonferroni adjustment for group comparison. Assumptions of homogeneity of variances were tested with Levene's test. One-way ANCOVA analyses have carried out to assess the impact of vertical implant position on group difference by adjusting the mean value of covariates. A " $p$ "-value of less than 0.05 was considered statistically significant.

\section{3 | RESULTS}

A total of 40 subjects was allocated randomly into two groups and 38 subjects finished the final visit at 12 months which included 18

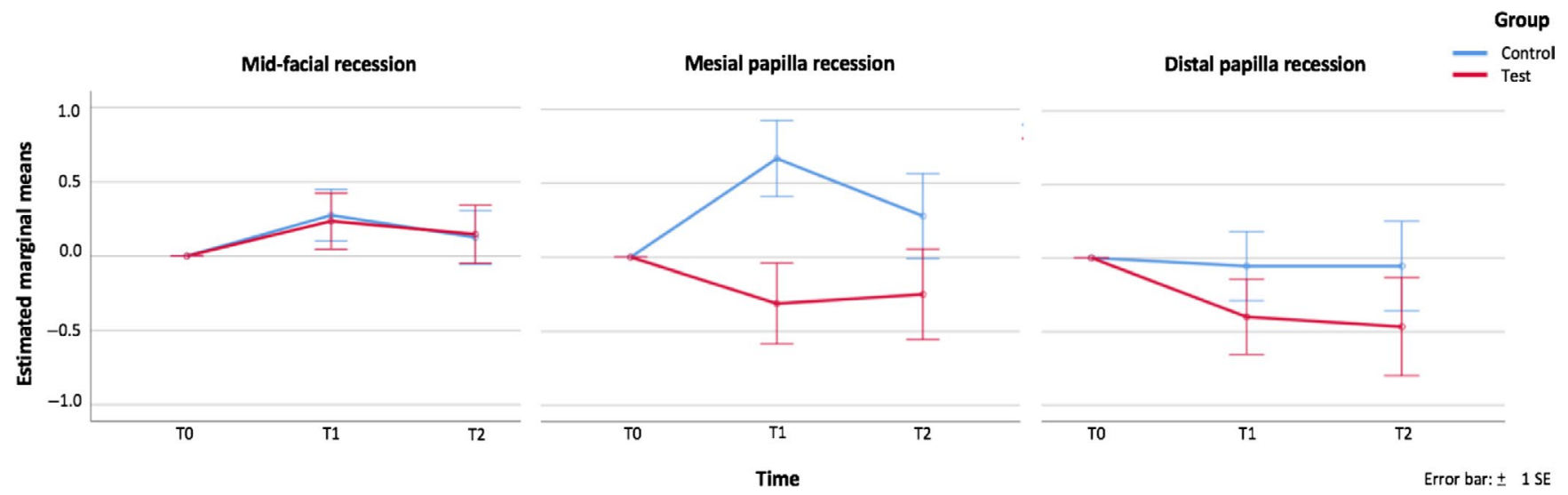

FIGURE 4 Graphs comparing changes in mid-facial level, papilla height at $T_{1}$ and $T_{2}$ between test and control groups. Changes at $T 1$ and $\mathrm{T} 2$ in mid-facial mucosa level and papilla height compared with the baseline level were reported here as positive value indicates recession and negative value indicates overgrowth (expressed in $\mathrm{mm}$ as mean $\pm S D$ ) for immediate provisionalization group (red line) and healing abutment group (blue line). In general, there were no statistically differences in these outcome measures between the groups at T1 (crown delivery) and T2 (final visit). The mean mid-facial level change at T1 and T2 was $0.2 \pm 0.8 \mathrm{~mm}$ and $0.1 \pm 0.9 \mathrm{~mm}$ in the test group. The corresponding values were $0.3 \pm 0.8 \mathrm{~mm}$ and $0.1 \pm 0.7 \mathrm{~mm}$ in the control group. Next, the mean mesial papilla height change at T1 and T2 was $-0.3 \pm 1.0 \mathrm{~mm}$ and $-0.3 \pm 1.3 \mathrm{~mm}$ in the test group and $0.7 \pm 1.2$ and $0.3 \pm 1.1 \mathrm{~mm}$ in the control group. Immediate provisionalization (test) group displayed significantly less recession at mesial papilla height compared to the control group at T1 ( $p=0.01$ ), and healing abutment (control) group demonstrated significant changes within time $(p=0.04)$. Finally, the mean distal papilla height change at T1 and T2 was $-0.4 \pm 1.0 \mathrm{~mm}$ and $-0.5 \pm 1.4 \mathrm{~mm}$ in the test group and $-0.1 \pm 1.0$ and $-0.1 \pm 1.2$ in the control group 
subjects in the test group (10 anteriors, eight premolars) and 20 subjects in the control group (10 anteriors, 10 premolars). The implant survival rate was $100 \%$ in the control group and $90 \%$ (two implants failed to achieve osseointegration) in the test group. There were no statistically significant differences in subject background information and potential confounding factors between the two groups, except for vertical implant position (Table 1). The implant platform level from the facial mucosal level was $2.7 \pm 0.7$ and $3.4 \pm 0.6 \mathrm{~mm}$, respectively $(p=0.004)$. All implants in both groups were grafted with human allograft particles in buccal gaps. Changes at $T_{1}$ and $T_{2}$ in mid-facial mucosa level and papilla level compared with the baseline level were reported as a positive value, which indicates recession, and a negative value, which indicates overgrowth. The mean midfacial level change at $T_{1}$ and $T_{2}$ was $0.2 \pm 0.8 \mathrm{~mm}$ and $0.1 \pm 0.9 \mathrm{~mm}$ in the test group. The corresponding values were $0.3 \pm 0.8 \mathrm{~mm}$ and $0.1 \pm 0.7 \mathrm{~mm}$ in the control group. The results of two-way mixed ANOVA showed there was no statistically significant interaction between the intervention (group) and time on mid-facial recession $(p=0.93$ ). There was no significant difference in the mid-facial mucosal level at the different time points $(p=0.11)$ and between the groups ( $p=0.97$ ) (Figure 4). After adjustment for vertical position of implant, there was no statistically significant difference of mid-facial recession between two group at T1 $(p=0.86)$ and T2 $(p=0.23)$. Next, the mean mesial papilla height change at $T_{1}$ and $T_{2}$ was $-0.3 \pm 1.0 \mathrm{~mm}$ and $-0.3 \pm 1.3 \mathrm{~mm}$ in the test group and $0.7 \pm 1.2$ and $0.3 \pm 1.1 \mathrm{~mm}$ in the control group. There was a statistically significant interaction between group and time on mesial papilla height changes $(p=0.04)$. Results also showed a significant effect of time on mesial papilla changes for the control group ( $p=0.04)$, but not in the test group $(p=0.5)$. There was a significant difference in mesial papilla recession between two groups at T1 $(p=0.04)$, but not at the T2 stage $(p=0.21)$ (Figure 4$)$. When examined the mean distal papilla height change at $T_{1}$ and $T_{2}$, there were no significant interactions between group and time $(p=0.68)$, within both groups at different time points $(p=0.33)$ and between groups $(p=0.32$ ). Both sides of papilla failed to demonstrate significant difference between groups after adjusting the vertical position of implant. The mean marginal bone level change at $T_{1}$ and $T_{2}$ compared with the baseline bone level was $0.7 \pm 0.6$ and $0.8 \pm 0.7 \mathrm{~mm}$ in the test group and $0.6 \pm 0.6$ and $0.8 \pm 0.6$ in the control group. Two-way ANOVA analysis for marginal bone loss revealed no significant interaction between group and time ( $p=0.22)$, within time points $(p=0.22)$ and between groups ( $p=0.63$ ). After adjusting for vertical position of implant, there was no overall significant difference of $\mathrm{MBL}$ between groups. The mean probing depth of implants at 12 months for Plaque index, gingival index and aesthetic scores (PES, WES) at 12 months was not significantly different between the two groups at 12 months ( $p=0.44,0.55,0.75$ and 0.87 , respectively).

The CBCT linear measurements of buccal crestal spatial changes were $1.6 \pm 0.6$ and $1.7 \pm 0.6 \mathrm{~mm}$ in test and control group, respectively. In the horizontal element of crestal changes, test and control groups were $1.5 \pm 0.7$ and $1.4 \pm 0.6 \mathrm{~mm}$; and the crest height changes were $0.3 \pm 0.4$ and $0.7 \pm 0.6 \mathrm{~mm}$. The palatal aspects of crestal bone spatial changes between test and control group were $1.1 \pm 0.45$ and $1.3 \pm 0.74 \mathrm{~mm}$ (horizontally: $0.6 \pm 0.6$ and $0.6 \pm 0.5 \mathrm{~mm}$; vertically: $1.0 \pm 0.5$ and $1.1 \pm 0.7 \mathrm{~mm}$ ). All of the above measurements were not significantly different between two groups, except for the vertical component of crestal changes ( $p=0.02$ ). After adjusting for vertical position of implant, the difference between test and control group remained significant ( $p=0.02$ ).

The peri-implant buccal bone wall thickness at implant platform at $T_{1}$ presented with reduction of $0.6 \pm 0.7$ versus $0.7 \pm 0.5 \mathrm{~mm}$ compared with pre-extraction outer bone plate (test vs. control, respectively). The horizontal resorption of buccal bone plate at the implant platform amounted to $23.9 \%$ (test) and $22.4 \%$ (control). All the peri-implant bone thickness or reduction of bone thickness at

TA B LE 2 Comparison of buccal and palatal bone thickness at 4 months post-implant (T1) at different levels above implant platform and the reduction of thickness compared to pre-extraction (TO) outer surface of bone plate

\begin{tabular}{|c|c|c|c|c|c|c|c|c|c|}
\hline & \multicolumn{3}{|c|}{$\begin{array}{l}\text { Implant to pre-extraction outer } \\
\text { surface of bone plate }\end{array}$} & \multicolumn{3}{|c|}{$\begin{array}{l}\text { Post-implant bone thickness } \\
(\mathrm{mm})\end{array}$} & \multicolumn{3}{|c|}{$\begin{array}{l}\text { Reduction after implant placement in } \mathrm{mm} \text { (per- } \\
\text { centage of reduction \%) }\end{array}$} \\
\hline & Test & Control & $p$-value & Test & Control & $p$-value & Test & Control & $p$-value \\
\hline $\begin{array}{l}\text { Buccal bone thick- } \\
\text { ness at } 0 \mathrm{~mm}\end{array}$ & $2.7 \pm 0.9$ & $3.3 \pm 0.9$ & 0.66 & $2.3 \pm 1.4$ & $2.5 \pm 1.2$ & 0.66 & $0.6 \pm 0.7(23.9 \%)$ & $0.7 \pm 0.5(22.3 \%)$ & 0.66 \\
\hline $2 \mathrm{~mm}$ & $3.3 \pm 1.3$ & $3.2 \pm 1.0$ & 0.9 & $2.9 \pm 1.7$ & $2.7 \pm 1.2$ & 0.74 & $0.5 \pm 0.6(23.1 \%)$ & $0.5 \pm 0.5(16.2 \%)$ & 0.73 \\
\hline $6 \mathrm{~mm}$ & $2.5 \pm 1.8$ & $2.3 \pm 1.3$ & 0.81 & $2.2 \pm 1.8$ & $1.9 \pm 1.2$ & 0.54 & $0.3 \pm 0.5(21.1 \%)$ & $0.5 \pm 0.5(18.6 \%)$ & 0.26 \\
\hline $8 \mathrm{~mm}$ & $2.3 \pm 1.7$ & $2.1 \pm 1.2$ & 0.72 & $2.1 \pm 1.7$ & $1.7 \pm 1.2$ & 0.41 & $0.1 \pm 0.6(16.4 \%)$ & $0.4 \pm 0.4(15.2 \%)$ & 0.23 \\
\hline $\begin{array}{l}\text { Palatal bone thick- } \\
\text { ness at } 0 \mathrm{~mm}\end{array}$ & $1.3 \pm 1.0$ & $1.3 \pm 0.6$ & 0.97 & $1.1 \pm 1.0$ & $1.0 \pm 0.5$ & 0.68 & $0.3 \pm 0.4(18.1 \%)$ & $0.4 \pm 0.5$ (28.0\%) & 0.34 \\
\hline $2 \mathrm{~mm}$ & $2.1 \pm 1.4$ & $2.2 \pm 0.9$ & 0.88 & $2.0 \pm 1.3$ & $1.9 \pm 0.9$ & 0.85 & $0.1 \pm 0.3(3.4 \%)$ & $0.2 \pm 0.3(12.4 \%)$ & 0.20 \\
\hline
\end{tabular}




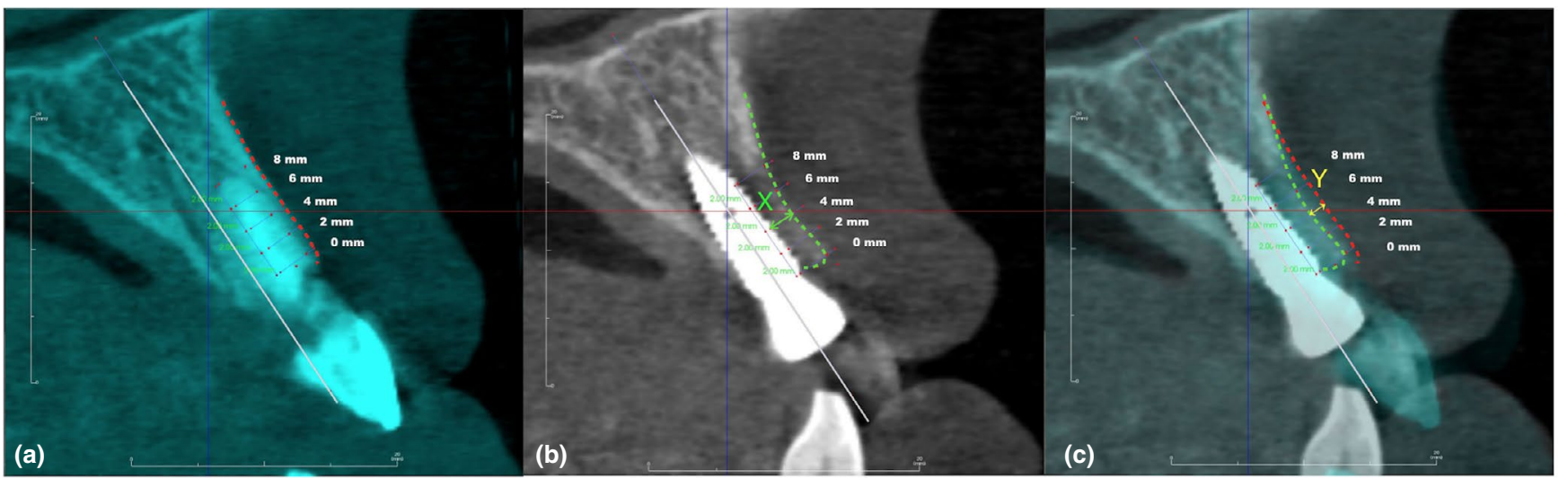

FIGURE 5 Illustrates measurement between two time points: baseline and 4 months after implant placement. Buccal bone thickness reduction at 4 months post-implant (T1) at different measurement levels ( $2 \mathrm{~mm}$ interval) above the implant platform in CBCT superimposed analysis. (a) Pre-extraction, the red dot line represents the most outer surface of the buccal bone plate of residual root; (b) Post-implant placement at T1, the green dot line represents the most outer surface of the buccal bone plate of implant; post-implant buccal bone thickness was measured (green arrow: X); (c) Superimposed of two images (T0 and T1) showed the amount of resorption (yellow arrow: $Y$ ); implant to pre-extraction outer surface of bone plate was calculated as $X+Y$, and the resorption percentage was calculated as $Y / X+Y$

different levels of 2-mm interval above the implant platform failed to show a significant difference between two groups; furthermore, after adjusting for the vertical position of implant they still failed to show significant differences (Table 2, Figure 5). Results of twoway mixed ANOVA showed that the horizontal, vertical crestal bone changes and the bone thickness reduction (percentage) at the platform above did not have an impact on the mid-facial recession over time ( $p=0.97,0.62,0.96)$.

\section{4 | DISCUSSION}

Aesthetic outcomes of immediately placed implants and immediate provisionalization have recently been a popular topic of interest. Immediate implant placement was reported to be associated with a higher risk of mucosal recession (Cosyn et al., 2012; Kan, Rungcharassaeng, et al., 2011). Immediate provisionalization was thought to provide physical support for facial mucosal level; however, limited evidence (Block et al., 2009) showed benefit of immediate provisionalization on maintaining mid-facial mucosal level. Results from this study demonstrated that at 12 months, there is minimal change in facial mucosal level, suggesting that immediate implant placement can sustain facial mucosal level regardless of provisionalization. Yet, the mesial papillae demonstrated even overgrowth over the immediate provisionalization compared to the reduction in the control group and most of dimensional changes occurred at early stage of healing, which was in line with other observations (Cosyn et al., 2013; De Rouck, Collys, \& Cosyn, 2008). Whether this result will stand the test of time remains to be determined. On the other hand, immediate provisionalization fails to provide additional aesthetic benefit. It is possible that implant positioning instead is the most prominent factor for determining the facial mucosal level. Implants with a buccal shoulder position showed three times more recession than implants with a lingual shoulder position (Evans \& Chen, 2008).
In this study, implants were placed on average $2.7 \mathrm{~mm}$ from the buccal plate and the gap was filled with particulate bone allograft, resulting in the observed minimal changes. Although the vertical component of the crest bone changes was significantly less with the immediate provisionalization in the early stage of healing (4-month), this difference did not translate significantly to the clinical mid-facial mucosa level at 4-month or at the final 12-month observation. It was in concordance with the previous clinical report that marginal tissue recession was not correlated with the changes in vertical crest position; instead, it was more associated with the bucco-lingual position of the implant shoulder (Chen, Darby, \& Reynolds, 2007). The results from this study suggested that when placed implant in an ideal 3D position, with or without immediate provisionalization during immediate implant placement did not make any difference in terms of mucosal recession or final aesthetic outcomes. Hence, if the implant is placed in an ideal cingulum and optimum 3D position then immediate provisionalization may not be needed to avoid the potential risk of unnecessary occlusal trauma that may cause implant to fail. In this scenario, anatomic abutment should be adequate in restoring the case without jeopardizing the osseointegration.

Additionally, papilla height changes were minimal for both groups at 12 months. This result was expected since the interdental tissue height of single implants is primarily determined by the crestal bone height of adjacent teeth (Kan, Rungcharassaeng, Umezu, \& Kois, 2003). No significant change in crestal bone height of adjacent teeth was observed.

A flapless and open wound approach without an attempt for primary closure was adopted in this study, which is commonly used by other groups (Chen, Darby, Reynolds, \& Clement, 2009; Cosyn et al., 2011; Kan, Rungcharassaeng, et al., 2011) by the benefit of high healing potential of extraction sockets. In contrast, other studies emphasized the need of primary closure after an immediate implant placement procedure (Lazzara, 1989; Tonetti et al., 2017). Extensive soft tissue management, length of time required and patient morbidity 
are the major drawbacks of attempting primary closure. One study with the closed approach showed an inferior aesthetic outcome as a result of immediate implant placement (Tonetti et al., 2017). In light of the positive outcomes of this study, which differs from the disadvantages of attempting primary closure, the flapless and open wound approach might be favoured for immediate implant surgery.

Limitations of this study include (a) inability to mask the examiners, (b) inadequate sample size to detect differences in marginal bone levels due to two failed test implants and (c) slight different implant apico-coronal position between test and control groups. Biases may be introduced because the examiners were aware of the obvious treatment differences (temporary crown or healing abutment). However, the statistician was masked to the group assignment. It is generally accepted to place implants with the platform at $3 \mathrm{~mm}$ apically to the mucosal margin. The mean vertical implant positions were 2.7 and $3.4 \mathrm{~mm}$ in the test and control groups; although with statistically significant difference, the results after adjusting for the vertical position of implant demonstrated the minimal influence of this factor on primary outcome. We did note that two test implants failed to achieve osseointegration during the 1st month of healing and were excluded from the study. This may have resulted in under power in examining the influence of marginal bone level changes. The most probable reason for early failure is excessive occlusal load since both patients had no posterior support due to missing posterior teeth. The impact of apico-coronal implant position on crest bone loss is inconsistent in the literature (Ercoli et al., 2017; Hartman \& Cochran, 2004; Saleh et al., 2018; Valles et al., 2018). The early vertical loss from crest remodelling was significantly less with immediate temporalization at 4 months, although this difference might not be clinically significant. Whether soft tissue margin is influenced by vertical implant level at a later time is not clear; hence, a longer follow-up is needed to answer this question.

\section{5 | CONCLUSION}

This randomized controlled trial demonstrated successful aesthetic and functional outcomes of single immediate implant placement with or without immediate provisionalization in the aesthetic zone in short term. Both groups resulted in minimal changes in marginal level and papilla height, compared with pre-extraction. Immediate provisionalization did not show better aesthetic outcomes than using flared healing abutment.

\section{CONFLICT OF INTEREST}

The authors do not have any financial interests, either directly or indirectly, in the products or information listed in the paper except Dr. Wang occasionally received honorarium for speaking on behalf of Neobiotech. The study was partially supported by a gift donated from Neobiotech, South Korea and the University of Michigan Graduate Student Research Grant. Furthermore, Neobiotech provided implants and implant prostheses for the study.

\section{ACKNOWLEDGEMENTS}

The authors would like to thank Mrs. Alicia Backer, Clinical Coordinator, Veronica Slayton and Cynthia Lawson, Dental Assistants, for coordinating this study as well as Dr. Guo-Hao Lin (currently, Clinical Assistant Professor at the Health Sciences, School of Dentistry, University of California, San Francisco, San Francisco, CA 94143, USA) for his involvement in the initial stage of this study (e.g. helping to develop the protocol as well as making some surgical guides for implant placement).

\section{ORCID}

Hsun-Liang Chan (iD https://orcid.org/0000-0001-5952-0447

Hom-Lay Wang iD https://orcid.org/0000-0003-4238-1799

\section{REFERENCES}

Araujo, M. G., Linder, E., \& Lindhe, J. (2011). Bio-Oss collagen in the buccal gap at immediate implants: A 6-month study in the dog. Clin Oral Implants Res, 22(1), 1-8. https://doi. org/10.1111/j.1600-0501.2010.01920.x

Block, M. S., Mercante, D. E., Lirette, D., Mohamed, W., Ryser, M., \& Castellon, P. (2009). Prospective evaluation of immediate and delayed provisional single tooth restorations. Journal of Oral and Maxillofacial Surgery, 67(11 Suppl), 89-107. https://doi.org/10.1016/ j.joms.2009.07.009

Botticelli, D., Berglundh, T., \& Lindhe, J. (2004). Hard-tissue alterations following immediate implant placement in extraction sites. Journal of Clinical Periodontology, 31(10), 820-828. https://doi. org/10.1111/j.1600-051X.2004.00565.x

Chen, S. T., Darby, I. B., \& Reynolds, E. C. (2007). A prospective clinical study of non-submerged immediate implants: Clinical outcomes and esthetic results. Clin Oral Implants Res, 18(5), 552-562. https://doi. org/10.1111/j.1600-0501.2007.01388.x

Chen, S. T., Darby, I. B., Reynolds, E. C., \& Clement, J. G. (2009). Immediate implant placement postextraction without flap elevation. Journal of Periodontology, 80(1), 163-172. https://doi.org/10.1902/ jop. 2009.080243

Chen, S. T., Wilson, T. G. Jr, \& Hammerle, C. H. (2004). Immediate or early placement of implants following tooth extraction: Review of biologic basis, clinical procedures, and outcomes. International Journal of Oral and Maxillofacial Implants, 19(Suppl), 12-25.

Claffey, N., \& Shanley, D. (1986). Relationship of gingival thickness and bleeding to loss of probing attachment in shallow sites following nonsurgical periodontal therapy. Journal of Clinical Periodontology, 13(7), 654-657. https://doi.org/10.1111/j.1600-051X.1986.tb00861.x

Cochran, D. L., Morton, D., \& Weber, H. P. (2004). Consensus statements and recommended clinical procedures regarding loading protocols for endosseous dental implants. International Journal of Oral and Maxillofacial Implants, 19(Suppl), 109-113.

Cosyn, J., De Bruyn, H., \& Cleymaet, R. (2013). Soft tissue preservation and pink aesthetics around single immediate implant restorations: A 1-year prospective study. Clinical Implant Dentistry and Related Research, 15(6), 847-857. https://doi. org/10.1111/j.1708-8208.2012.00448.x

Cosyn, J., Eghbali, A., De Bruyn, H., Collys, K., Cleymaet, R., \& De Rouck, T. (2011). Immediate single-tooth implants in the anterior maxilla: 3-year results of a case series on hard and soft tissue response and aesthetics. Journal of Clinical Periodontology, 38(8), 746-753. https://doi.org/10.1111/j.1600-051X.2011.01748.x 
Cosyn, J., Hooghe, N., \& De Bruyn, H. (2012). A systematic review on the frequency of advanced recession following single immediate implant treatment. Journal of Clinical Periodontology, 39(6), 582-589. https://doi.org/10.1111/j.1600-051X.2012.01888.x

De Rouck, T., Collys, K., \& Cosyn, J. (2008). Immediate single-tooth implants in the anterior maxilla: a 1-year case cohort study on hard and soft tissue response. Journal of Clinical Periodontology, 35(7), 649657. https://doi.org/10.1111/j.1600-051X.2008.01235.x

Ercoli, C., Jammal, G., Buyers, M., Tsigarida, A. A., Chochlidakis, K. M., Feng, C., \& Caton, J. (2017). Influence of apico-coronal implant placement on post-surgical crestal bone loss in humans. Journal of Periodontology, 88(8), 762-770. https://doi.org/10.1902/ jop.2017.160802

Evans, C. D., \& Chen, S. T. (2008). Esthetic outcomes of immediate implant placements. Clinical Oral Implants Research, 19(1), 73-80. https://doi.org/10.1111/j.1600-0501.2007.01413.x

Ferrus, J., Cecchinato, D., Pjetursson, E. B., Lang, N. P., Sanz, M., \& Lindhe, J. (2010). Factors influencing ridge alterations following immediate implant placement into extraction sockets. Clinical Oral Implants Research, 21(1), 22-29. https://doi. org/10.1111/j.1600-0501.2009.01825.x

Fu, J.-H., Yeh, C.-Y., Chan, H.-L., Tatarakis, N., Leong, D. J. M., \& Wang, H.-L. (2010). Tissue biotype and its relation to the underlying bone morphology. Journal of Periodontology, 81(4), 569-574. https://doi. org/10.1902/jop.2009.090591

Furhauser, R., Florescu, D., Benesch, T., Haas, R., Mailath, G., \& Watzek, G. (2005). Evaluation of soft tissue around single-tooth implant crowns: The pink esthetic score. Clinical Oral Implants Research, 16(6), 639-644. https://doi.org/10.1111/j.1600-0501.2005.01193.x

Gallucci, G. O., Hamilton, A., Zhou, W., Buser, D., \& Chen, S. (2018). Implant placement and loading protocols in partially edentulous patients: A systematic review. Clin Oral Implants Res, 29(Suppl 16), 106-134. https://doi.org/10.1111/clr.13276

Hartman, G. A., \& Cochran, D. L. (2004). Initial implant position determines the magnitude of crestal bone remodeling. Journal of Periodontology, 75(4), 572-577. https://doi.org/10.1902/jop.2004.75.4.572

Kan, J. Y., Roe, P., Rungcharassaeng, K., Patel, R. D., Waki, T., Lozada, J. L., \& Zimmerman, G. (2011). Classification of sagittal root position in relation to the anterior maxillary osseous housing for immediate implant placement: A cone beam computed tomography study. International Journal of Oral and Maxillofacial Implants, 26(4), 873-876.

Kan, J. Y., Rungcharassaeng, K., \& Lozada, J. L. (2005). Bilaminar subepithelial connective tissue grafts for immediate implant placement and provisionalization in the esthetic zone. Journal of the California Dental Association, 33(11), 865-871.

Kan, J. Y., Rungcharassaeng, K., Lozada, J. L., \& Zimmerman, G. (2011). Facial gingival tissue stability following immediate placement and provisionalization of maxillary anterior single implants: A 2- to 8-year follow-up. International Journal of Oral and Maxillofacial Implants, 26(1), 179-187.

Kan, J. Y., Rungcharassaeng, K., Sclar, A., \& Lozada, J. L. (2007). Effects of the facial osseous defect morphology on gingival dynamics after immediate tooth replacement and guided bone regeneration: 1-year results. Journal of Oral and Maxillofacial Surgery, 65(7 Suppl 1), 13-19. https://doi.org/10.1016/j.joms.2007.04.006

Kan, J. Y., Rungcharassaeng, K., Umezu, K., \& Kois, J. C. (2003). Dimensions of peri-implant mucosa: An evaluation of maxillary anterior single implants in humans. Journal of Periodontology, 74(4), 557-562. https://doi.org/10.1902/jop.2003.74.4.557

Koticha, T., Fu, J. H., Chan, H. L., \& Wang, H. L. (2012). Influence of thread design on implant positioning in immediate implant placement. Journal of Periodontology, 83(11), 1420-1424. https://doi. org/10.1902/jop.2012.110665

Lazzara, R. J. (1989). Immediate implant placement into extraction sites: Surgical and restorative advantages. International Journal of Periodontics \& Restorative Dentistry, 9(5), 332-343.

Lin, G. H., Chan, H. L., Bashutski, J. D., Oh, T. J., \& Wang, H. L. (2014). The effect of flapless surgery on implant survival and marginal bone level: A systematic review and meta-analysis. Journal of Periodontology, 85(5), e91-103. https://doi.org/10.1902/jop.2013.130481

Miyamoto, Y., \& Obama, T. (2011). Dental cone beam computed tomography analyses of postoperative labial bone thickness in maxillary anterior implants: Comparing immediate and delayed implant placement. International Journal of Periodontics \& Restorative Dentistry, 31(3), 215-225.

Oh, T. J., Shotwell, J. L., Billy, E. J., \& Wang, H. L. (2006). Effect of flapless implant surgery on soft tissue profile: A randomized controlled clinical trial. Journal of Periodontology, 77(5), 874-882. https://doi. org/10.1902/jop.2006.050169

Raes, F., Cosyn, J., Crommelinck, E., Coessens, P., \& De Bruyn, H. (2011). Immediate and conventional single implant treatment in the anterior maxilla: 1-year results of a case series on hard and soft tissue response and aesthetics. Journal of Clinical Periodontology, 38(4), 385394. https://doi.org/10.1111/j.1600-051X.2010.01687.x

Saleh, M. H. A., Ravidà, A., Suárez-López del Amo, F., Lin, G.-H., Asa'ad, F., \& Wang, H.-L. (2018). The effect of implant-abutment junction position on crestal bone loss: A systematic review and meta-analysis. Clinical Implant Dentistry and Related Research, 20(4), 617-633. https://doi.org/10.1111/cid.12600

Suarez, F., Chan, H. L., Monje, A., Galindo-Moreno, P., \& Wang, H. L. (2013). Effect of the timing of restoration on implant marginal bone loss: A systematic review. Journal of Periodontology, 84(2), 159-169. https://doi.org/10.1902/jop.2012.120099

Tonetti, M. S., Cortellini, P., Graziani, F., Cairo, F., Lang, N. P., Abundo, R., ... Wetzel, A. (2017). Immediate versus delayed implant placement after anterior single tooth extraction: The timing randomized controlled clinical trial. Journal of Clinical Periodontology, 44(2), 215-224. https://doi.org/10.1111/jcpe.12666

Valles, C., Rodriguez-Ciurana, X., Clementini, M., Baglivo, M., Paniagua, B., \& Nart, J. (2018). Influence of subcrestal implant placement compared with equicrestal position on the peri-implant hard and soft tissues around platform-switched implants: A systematic review and meta-analysis. Clinical Oral Investigations, 22(2), 555-570. https://doi. org/10.1007/s00784-017-2301-1

How to cite this article: Chan H-L, George F, Wang I-C, Suárez López del Amo F, Kinney J, Wang H-L. A randomized controlled trial to compare aesthetic outcomes of immediately placed implants with and without immediate provisionalization. J Clin Periodontol. 2019;46:1061-1069. https://doi.org/10.1111/jcpe.13171 